\title{
Cloning and bioethical thinking
}

Sir - Axel Kahn reminds us, rightly, that Kant's famous principle states: "Respect for human dignity requires that an individual is never used... exclusively as a means", and suggests that I have ignored the crucial use of the term 'exclusively' (Nature 388, 320; 1997).

I did not, of course, and I am happy with Kahn's reformulation of the principle. It is not that Kant's principle does not have powerful intuitive force but that it is so vague and open to selective interpretation, and its scope for application is consequently so limited, that its utility as one of the "fundamental principles of modern bioethical thought", as Kahn describes it, is virtually zero.

Kahn himself rightly points out that debates about the moral status of the human embryo are debates about whether embryos fall within the scope of Kant's or any other moral principles concerning persons; so the principle itself is not illuminating in this context. Applied to the creation of individuals which are, or will become, autonomous, it has limited application. True, it rules out slavery, but so do other principles based on autonomy and rights.
If you are interested in the ethics of creating people, then, so long as existence is in the created individual's own best interests, and so long as the individual will have the capacity for autonomy like any other, the motives for which the individual was created are either morally irrelevant or subordinate to other moral considerations.

So even where, for example, a child is engendered exclusively to provide 'a son and heir' (as in many cultures), it is unclear how or whether Kant's principle applies. Either other motives are also attributed to the parent to square parental purposes with Kant, or the child's eventual autonomy, and its clear and substantial interest in or benefit from existence, take precedence over the comparatively trivial issue of parental motives. Either way, the "fundamental principle of modern bioethical thought" is unhelpful.

I am therefore at a loss to know why Kahn invokes it with such dramatic assurance or how he thinks it applies to the ethics of human cloning. It comes down to this: either the ethics of human cloning turn on the creation or use of human embryos, in which case, as Kahn himself says, "in reality the debate is about the status of the human embryo" and Kant's principle must wait upon the outcome of that debate; or it is about the ethics of producing clones that will become autonomous human persons.

In the latter case, as David Shapiro rightly comments (Nature 388, 511; 1997), the ethics of their creation are, from a Kantian perspective, not dissimilar to that of other forms of assisted reproduction or indeed to the ethics of the conduct of parents concerned exclusively with producing an heir or preserving their genes or, as is sometimes alleged, making themselves eligible for public housing and debates about whether these are exclusive intentions are sterile or irresolvable.

When Kahn asks: "Is Harris announcing the emergence of a revisionist tendency in bioethical thinking?", the answer must be rather that I am pleading for the emergence of "bioethical thinking" as opposed to empty rhetoric of invoking resonant principles with no conceivable or coherent application to the problem at hand.

John Harris

Institute of Medicine, Law and Bioethics,

University of Manchester,

Oxford Road, Manchester M13 9PL, UK

\section{European centres for disease control}

Sir - The US Centers for Disease Control (CDC), in Atlanta, Georgia, are a federal organization with two missions: disease control and research. Its size (several thousand people) and centralized concept make it a powerful tool for addressing the challenge of emerging and re-emerging infectious diseases (ERID), through one of its main departments, the National Center for Control of Infectious Diseases.

There are no comparable structures to the CDC in Europe. Nevertheless, such a centralized centre could boost and coordinate European efforts to research and control these diseases. Although networks can help, they are no substitute for a real centre, with researchers from different countries interacting daily. The European Laboratory for Particle Physics (CERN) and the European Molecular Biology Organization (EMBO) are successful examples. The proposed centre, whose title might be European Centre for Control of Infectious Diseases (ECCID), should have a similar international status.

Apart from control and epidemiological surveillance, ECCID should have the following components. First, basic research, because medicine no longer controls the ERID problem. Second, training. Third, strong connections with developing countries, in which the ERID problem is especially devastating. ECCID should coordinate its efforts with the World Health Organization and with national structures such as the London School of Tropical Medicine in Britain and the Instituts Pasteurs d'Outre-Mer and ORSTOM in France, which have a long experience of collaborative research in developing countries.

\section{Michel Tibayrenc}

Centre d'Etudes sur le Polymorphisme

des Microorganismes (CEPM),

UMR CNRS/ORSTOM 9926, BP 5045,

34032 Montpellier Cedex 1, France

e-mail:Michel.Tibayrenc@cepm.mpl.orstom.fr

\section{Straight talking}

Sir — The review by the linguist David Poeppel of The Symbolic Species: The CoEvolution of Language and the Brain by the neuroscientist Terrence Deacon (Nature $\mathbf{3 8 8}, \mathbf{7 3 4}$; 1997) sounds similar to a priest defending an established and powerful religion.

Where science and religion should differ is the way in which new ideas are treated.
Deacon makes a good case for a theory of evolution of language in his book, which is dismissed in Poeppel's review as merely a willingness to contribute an unimaginative opinion.

Deacon was even attacked for comparing primates with humans in his book. Unless one denies that humans evolved from primates, looking for evolutionary cues of language in nonhuman primates can only add to our knowledge.

After all, our language capacity does not come overnight and we are not the only species that talks and listens.

Until we fully understand the mechanisms underlying human speech and language, we should not ridicule others for suggesting alternative explanations to the long-standing problem of language evolution. The debate should not be trivialized to an argument between 'good guys' and 'bad guys'. In science, we should believe only in the truth, not in one view or the other.

Siddhartha C. Kadia

Xiaoqin Wang

Laboratory of Auditory Neurophysiology,

Department of Biomedical Engineering,

Johns Hopkins University School of Medicine,

Baltimore, Maryland 21205, USA

e-mail:xwang@bme.jhu.edu 